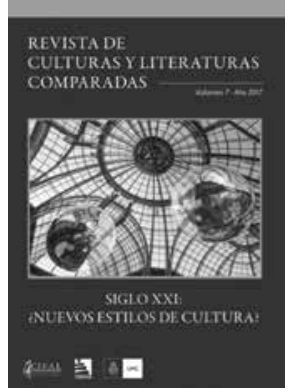

\title{
Revista de Culturas y \\ Literaturas Comparadas de la Facultad de Lenguas, Universidad Nacional de Córdoba
}

\author{
Cristina Elgue-Martini \\ Universidad Nacional de Córdoba
}

La idea de crear una revista científica en nuestro medio para coadyuvar al diálogo académico entre especialistas en literatura comparada fue esbozada por Jean Bessière en 2004, en ocasión de las Primeras Jornadas Internacionales sobre Memoria Cultural organizadas por nuestra Facultad conjuntamente con el Proyecto ACUME (Approaching Cultural Memory) de la Comunidad Europea y con el apoyo del Instituto Italiano de Cultura y de la Alianza Francesa de Córdoba. El proyecto se concretó en 2007 gracias al entusiasta esfuerzo de todos y cada uno de nuestros colegas investigadores.

La Revista de Culturas y Literaturas Comparadas refleja un desarrollo sostenido de más de tres décadas en el campo del comparatismo y constituye un espacio de intercambio y profundización de líneas de investigación y de encuentros científicos nucleados en torno a temáticas específicas, de allí que cada número establezca un área temática particular. Su aproximación al comparatismo responde a los más recientes paradigmas teórico-metodológicos, que conciben a los estudios comparados como diálogo no limitado a obras literarias en distintas lenguas, sino como estudios que consideran a los textos literarios en términos de su relación con lo que está más allá de la literatura, y, en su acepción más amplia, como contacto entre diversos textos culturales. La revista aspiró en un primer momento a acrecentar y difundir los valiosos aportes que se generan en el Área de Investigación en Literaturas y Culturas Comparadas de nuestra Facultad, como así también desde la Maestría en Literaturas y Culturas Comparadas, pero, también desde un comienzo, apuntó a incorporar las reflexiones de especialistas internacionales.

El volumen 1 recoge fundamentalmente los trabajos presentados en el coloquio Ulises a través del tiempo y del espacio, Coloquio Internacional de Literaturas y Culturas Comparadas que contó con la presencia de Franco Ferrucci, especialista italiano del mito homérico de Rutgers University, y fue organizado por el entonces Centro de Investigación en Literatura y Cultura de nuestra Facultad entre el 24 y 26 de agosto

\footnotetext{
- Tiene formación de Grado en Lengua y Literatura Inglesa y en Letras Modernas, y de Posgrado en Lingüística y en Literatura Comparada. Es Doctora por la Universidad Laval de Canadá y Profesora Emérita de la Universidad Nacional de Córdoba. Ha sido Decana de la Facultad de Lenguas y dirigió su Centro de Investigaciones. Dictó cursos de Posgrado en la Universidad Laval de Canadá e integra el cuerpo académico de diversas maestrías. Investigadora categoría I. Es vicepresidenta de la AAEA y de la Asociación Argentina de Literatura Comparada, de la que fue presidenta y socia fundadora. Premio de la Universidad Nacional de Córdoba, recibió las Palmas Académicas del Gobierno de Francia y el Diploma al mérito de la Asociación Argentina de Estudios Canadienses.
} 
de 2006, con el auspicio del Instituto Italiano de Cultura de Córdoba. Partiendo del Ulises homérico, los artículos dan cuenta de las distintas figuras del mito y variantes del viaje, construidas en Europa y América desde el pasado clásico hasta el presente, y plasmadas en la imagen y la palabra.

El volumen 2, publicado en 2008, se tituló Nostalgia y Melancolía: de pérdidas, locura y creatividad espiritual y reúne los trabajos presentados en dos coloquios organizados por nuestro Centro de Investigación junto a la Universidad de Bolońa y al Instituto Italiano de Cultura de Córdoba, con la colaboración del Instituto Goethe. La elección de las temáticas de estos coloquios refleja el interés generalizado por la melancolía y la nostalgia por parte tanto de gestores culturales como de académicos. Como dejan vislumbrar las reflexiones teóricas que abren este volumen, la melancolía ha constituido un tema recurrente en Occidente y el interés por parte de nuestro tercer milenio quedó decididamente manifiesto en la imponente exposición Melancolía, genio y locura de Occidente, realizada entre 2005 y 2006 en el Grand Palais de París, que propuso un recorrido cronológico de más de veinte siglos por la representación iconográfica de la melancolía a través de doscientas cincuenta obras. Con respecto a la nostalgia, la temática ha estado vigente desde la introducción del concepto en el campo de la medicina, en el siglo XVII, con connotaciones diferentes en los distintos periodos de la historia política y cultural de Occidente. Con el advenimiento de la posmodernidad, el término volvió al centro de los debates académicos, ya sea como nostalgia por el absoluto frente a la caída de los grandes relatos, como una forma de reacción frente al acelerado avance tecnológico, pero también como objeto de explotación comercial manipulado por la cultura mediática. Los trabajos académicos argentinos, alemanes e italianos reunidos en este volumen ponen de manifiesto la actualidad de ambas temáticas.

El volumen 3 fue publicado en 2011 y con el título de Tejidos Rizomáticos: interconexiones entre la literatura, las humanidades y las ciencias recoge los trabajos presentados por docentes-investigadores y miembros de equipos de investigación radicados en nuestra Facultad en las Jornadas Interconexiones entre la Literatura, las Humanidades y las Ciencias, que tuvieron lugar en la Facultad de Lenguas entre el 18 y el 20 de octubre de 2007, contando con la presencia de la Dra. Vita Fortunati de la Università degli Studi di Bologna en su carácter de coordinadora del Proyecto ACUME II (Interfacing Science, Literature and the Humanities), proyecto de la Red temática europea, que nuestra Facultad integraba en ese momento en calidad de associated partner. El proyecto cuestiona la idea tradicional de «influencia» a favor de una visión más dinámica de interconexión o interfacing. Los análisis críticos que integran el volumen confirman que la brecha entre las Humanidades y las Ciencias articulada durante el siglo XIX y consolidada a mediados del siglo XX constituye hoy un anacronismo.

Bajo el título Diálogos, sujetos, discursos, el volumen 4, que apareció en 2013, centra la atención en nuestra América como espacio de fronteras porosas, de construcción de identidades híbridas y sujetos subalternos, y espacio también de los primeros experimentos constitucionales que han hecho de la cosmovisión indígena su base filosófica y epistemológica. Atendiendo a la cronología, los artículos cubren gran parte de la historia de América: su espectro incluye tanto el tratamiento de la esclavitud en el Caribe colonial y del Arte y Vocabulario de la Lengua Quichua General de los Indios del Perú del siglo XVII, como un extenso corpus del siglo XXI. Con diferentes enfoques teóricos, los trabajos críticos estudian los procesos de transculturación en 
el contexto de un mundo globalizado y se adentran asimismo en la problemática que recientemente ha enfrentado el ser humano con la posibilidad de la extinción de la vida en el planeta. La ecología encuentra entonces un lugar en los análisis, donde la naturaleza no es simplemente marco contextual, sino que se constituye en principio metafísico, fundante de la realidad, o donde se plantea una concepción de armonía universal inscripta en un orden natural en el cual el hombre aparece como una parte de la naturaleza que garantiza su adecuado desarrollo.

El volumen 5, publicado en 2015, inicia la versión digital de la Revista de Culturas y Literaturas Comparadas de la Facultad de Lenguas. ${ }^{1}$. Con el título de Culturas y Literaturas en contextos transnacionales, el volumen propone una temática que, aunque de larga data en la historia de las culturas, se instala como problemática académica e incluso como campo de estudio hacia fines del siglo XX, y se fortalece en el nuevo milenio, en estrecha vinculación con el incremento de las migraciones y nuevas formas de movimiento de las poblaciones. En efecto, el siglo XXI es testigo de un notable aumento en el volumen y en la velocidad de estos movimientos poblacionales y fue objetivo central de este volumen estudiar cómo estos movimientos afectan la dinámica de las comunidades y la identidad de sus miembros.

Con el título Diálogos inter-oceánicos, el volumen 6 de la Revista, que fue publicado en 2016, abordó una problemática que es inherente al desarrollo de la mayoría de las culturas, y de la americana en especial, surgida, en gran medida, del diálogo entre el espacio americano y la teoría y práctica europea, a través de mecanismos referidos como mestizaje, criollización, creolización, antropofagia, transculturación, heterogeneidad, relación, por mencionar la terminología más citada. La lectura de los artículos que conforman este número de nuestra Revista confirma que no hay cultura moderna que no sea el resultado de procesos de mezclas, que la crítica, como dije, ha explicado, recurriendo a diferentes mediaciones teóricas. Este sexto volumen incluye, asimismo, testimonios europeos de la realidad y la literatura americana, así como estudios de tópicos abordados por autores europeos y americanos sin mediar contactos o influencias. Esta perspectiva apunta al «nuevo comparatismo", temática que es, también, tratada en el presente volumen. Además, algunos artículos incluyen el diálogo entre América Latina y los Estados Unidos, y la problemática de la traducción.

El volumen 7 de la Revista, aparecido en 1017, se preguntó: Siglo XXI: ¿Nuevos estilos de cultura? y se propuso indagar en los cambios producidos por el nuevo milenio en el «estilo de cultura» que predominó en nuestras sociedades occidentales en las últimas décadas del siglo XX, estilo de cultura referido casi unánimemente como posmodernismo. Concretamente, aspiraba a formular hipótesis sobre las estrategias de escritura y temáticas del siglo XXI: ¿una vuelta a estrategias de escritura más afines al realismo?, ¿neovictorianismo?, ¿giro ético?, ¿giro afectivo?, ¿postapocalipsis y antropoceno? Estos fueron algunos de los interrogantes. Este volumen incluyó un dossier con el título Culturas y Literaturas Comparadas: incubadora de conocimiento. Como expresó la Dra. Cristina Dalmagro en la presentación de esta sección:

Para celebrar los diez años de la creación de la revista y de la MCyLC, el Comité Académico de la carrera ha invitado a sus egresados a redactar un artículo que condense los resultados de sus investigaciones volcadas en tesis aprobadas. Por lo tanto, el presente dossier tiene una característica particular: todos los autores son egresados de la MCyLC; sus temáticas se corresponden con la investigación desarrollada en sus tesis de maestría... 
El volumen 8, el cual saldrá publicado en diciembre de 2018, versará sobre «La re-significación de los mitos: siglos XX y XXI».

\title{
Responsables de la Revista
}

Directora de la Revista desde sus comienzos y continúa: Cristina Elgue-Martini, PH.D.

Co-directora a partir de 2015 y continúa: Dra. Nadia Der-Ohannesian

Secretaria de Redacción 2008 y 2011: Dra. Liliana Tozzi

Secretaria de Redacción 2013 y 2014: Dra. Nadia Der-Ohannesian

Secretario de Redacción desde 2015 y continúa: Lic. Martín Tapia Kwiecien

\section{Consejo de Redacción Volumen 1 al 4}

Mirian Carballo, Norma Ceballos Aybar, Mónica Martínez de Arrieta, Adriana Massa,

Silvina Perrero de Roncaglia

Con posterioridad, y como resultado de la incorporación de nuevas carreras a la curricula de la Facultad de Lenguas, integró el Consejo de Redacción el Dr. Miguel Koleff, por el área de portugués, y la Dra. Cristina Dalmagro, como Directora de la Maestría en Culturas y Literaturas Comparadas. En noviembre de 2017 renunció la Dra. Mónica Arrieta por haber accedido a los beneficios de la jubilación y se incorporó en su reemplazo la Dra. Amelia Bogliotti.

\section{Comité Científico}

Jean Bessière (Université de la Sorbonne Nouvelle - Paris III)

Trinidad Blanco de García (Universidad Nacional de Córdoba)

Lisa Block de Behar (Universidad de la República - Uruguay)

Oscar Caeiro (Universidad Nacional de Córdoba)

Rolando Costa Picazo (Universidad de Buenos Aires)

Eduardo Coutinho (Universidade Federal do Rio de Janeiro)

Vita Fortunati (Università degli Studi di Bologna)

Lila Perrén de Velasco (Universidad Nacional de Córdoba - Universidad Católica de Córdoba)

\begin{abstract}
Nota
${ }^{1}$ Cabe aclarar que, con el tiempo, todos los números originalmente publicados en soporte papel fueron digitalizados y ya se encuentran disponibles, con acceso abierto al igual que cada uno de los números posteriores, en el repositorio de Revistas de la Universidad Nacional de Córdoba.
\end{abstract}

\section{Elgue-Martini, Cristina}

«Revista de Culturas y Literaturas Comparadas de la Facultad de Lenguas, Universidad Nacional de Córdo- 